\title{
PERFORATION OF THE INTERVENTRICULAR SEPTUM WITH SURVIVAL FOR FIVE YEARS
}

\author{
BY \\ CH. ALBAGLI* AND J. ESHCHAR \\ From Medical Department A, Asaf Harofe Government Hospital, Zrifin, Israel
}

Perforation of the interventricular septum after myocardial infarction was first described by Letham in 1845 (cit. Schiller, 1960). The first case diagnosed ante-mortem was Brunn's in 1923. Since then approximately 180 cases have been reported. Cooley et al. (1957) performed for the first time surgical repair of the defect, and since then several such attempts have been made. This therapeutic possibility requires an accurate and early diagnosis in order to select suitable patients.

We had an opportunity to treat a patient who survived for five years after septal perforation in cardiac infarction, in spite of several threatening complications.

\section{Case Report}

A 66-year-old man was first admitted to hospital in December 1955.

Apart from considerable productive cough for many years, the patient always felt well. His present illness began one month before admission with sudden, recurring sharp pain in the left side of the chest radiating to the back and epigastrium.

A normal temperature, pallor, and slight cyanosis were found. The blood pressure was $145 / 85 \mathrm{~mm}$. $\mathrm{Hg}$ and the pulse regular and rhythmic, 60 a minute. The chest was emphysematous and moist râles were heard over both lung bases. The neck veins were congested, and hepato-jugular reflux was present. A mesocardial systolic thrill of considerable intensity was felt and a grade IV systolic murmur heard in the fourth intercostal space near the left sternal border, radiating towards the right. The liver was hard and enlarged but not tender and was palpable $4 \mathrm{~cm}$. below the right costal margin. There was no œdema.

The erythrocyte sedimentation rate was $80 \mathrm{~mm}$. (Westergren). Blood urea, blood sugar, liver function tests, and urine examination were normal. Anæmia was present with hæmoglobin of $9 \cdot 7 \mathrm{~g} . / 100 \mathrm{ml}$. and $3,000,000$ erythrocytes per c.mm.; the white cell count was normal. The venous pressure was $20 \mathrm{~cm}$. water.

Radiological examination showed pronounced emphysema of the lungs with fibrosis in both upper fields and suspicion of bronchiectasis. The lungs were congested and both ventricles of the heart were enlarged. On the day following admission a cardiogram showed a postero-septal infarction in the Q-T stage (Fig. 1, line 1). This did not change appreciably during the next three months (Fig. 1, line 2).

The patient was thought to have had a postero-septal infarction of the myocardium most probably about one month before going into hospital and this had led to congestive failure. The tentative diagnosis of perforation of the interventricular septum was supported by the thrill and murmur described above.

Treatment with digitalis, diuretics, and antibiotics resulted in considerable subjective and objective improvement. The patient complained, however, of increasing epigastric pain, and after a barium meal a duodenal ulcer was suspected. On re-examination one month later narrowing of the pre-pyloric region was found together with a round filling defect, highly suspicious of a circular tumour. In view of the great improvement in the patient's cardio-pulmonary condition and the threat of malignancy with progressive pyloric stenosis, he was operated on under general anæsthesia in March 1956. A duodenal ulcer was found with severe pre-pyloric narrowing. Subtotal gastrectomy was performed.

The operation and post-operative course were without incident and the patient left hospital in a fair condition three weeks later. During the next three months he was admitted twice for respiratory tract

* Present address: Israel Defence Army, Doar Zvai 2166, Israel. 
infections and mild congestive heart failure. Until the fourth occasion in January 1961, the patient was ambulatory, although limited in his activities. He continued to cough and expectorate purulent sputum. From time to time he suffered from congestive failure, but he was never confined to bed for any length of time. He was now sent to hospital for increasing weakness and difficulty in breathing. Several hours before admission he collapsed and apparently lost consciousness for a short while.

On examination the patient was extremely pale and drowsy with a normal temperature, slight cyanosis, and shortness of breath. The blood pressure was $110 / 70 \mathrm{~mm}$. $\mathrm{Hg}$, slight œdema at the shins and basal râles were observed. The clinical signs in the heart remained unchanged. The neurological examination was negative.

The erythrocyte sedimentation rate was $26 \mathrm{~mm}$. (Westergren). The blood urea rose to $75 \mathrm{mg} . / 100 \mathrm{ml}$. The hæmoglobin measured $7 \mathrm{~g} . / 100 \mathrm{ml}$., with 3,000,000 erythrocytes/c.mm. A tendency to hæmolysis was noted. As before the reason for this unclassified anæmia remained obscure. In the electrocardiogram of the rather restless patient right bundle-branch block was noticed for the first time. The $T$ waves in the chest leads were now positive (Fig. 1, line 3). The patient remained drowsy and died on January 18, 1961.

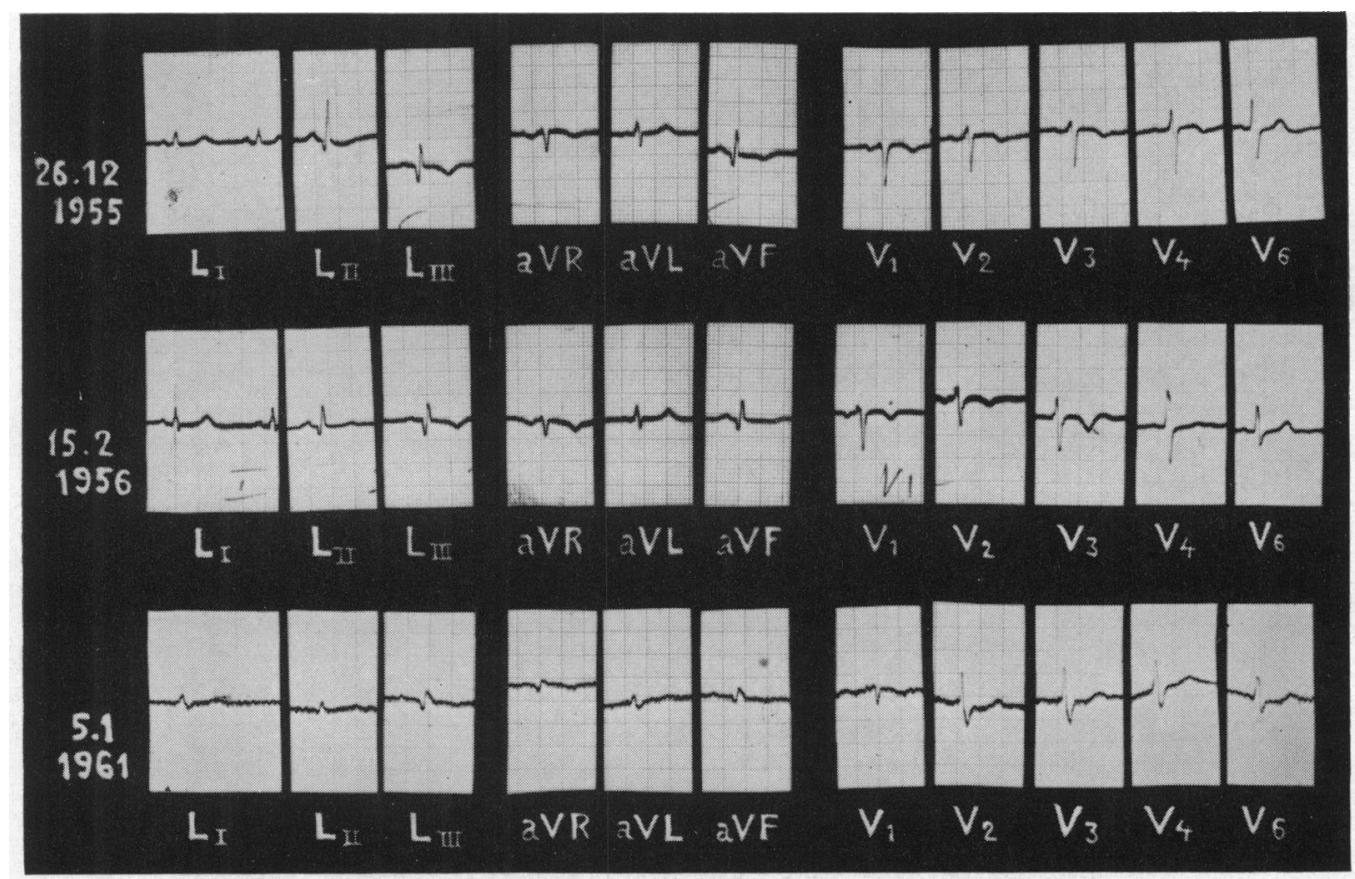

FIG. 1.-Electrocardiograms showing development during five years.

Autopsy. This was incomplete for reasons beyond our control. A small amount of serous fluid was found in both pleural spaces and bullous emphysema in both lungs. Diffuse bilateral saccular bronchiectasis with purulent contents was seen. The heart weighed $500 \mathrm{~g}$. and was generally enlarged, though mainly in its right half. Fibrotic areas stood out on the endocardium of the left ventricle and the interventricular septum: the latter showed an aneurysmal dilatation and in it a hole with a diameter of $0.5 \mathrm{~cm}$. (Fig. 2).

The histological examination of the myocardium confirmed the presence of old fibrotic changes in various areas, particularly in the septum and around the perforation. There were no signs of a recent myocardial infarction. The coronary arteries, though narrow, did not reveal any severe arteriosclerotic changes. In contrast with this latter finding, arteriosclerosis was conspicuous in the aorta. We were not in a position to examine the skull and its contents where we expected to find the possible cause of death. 


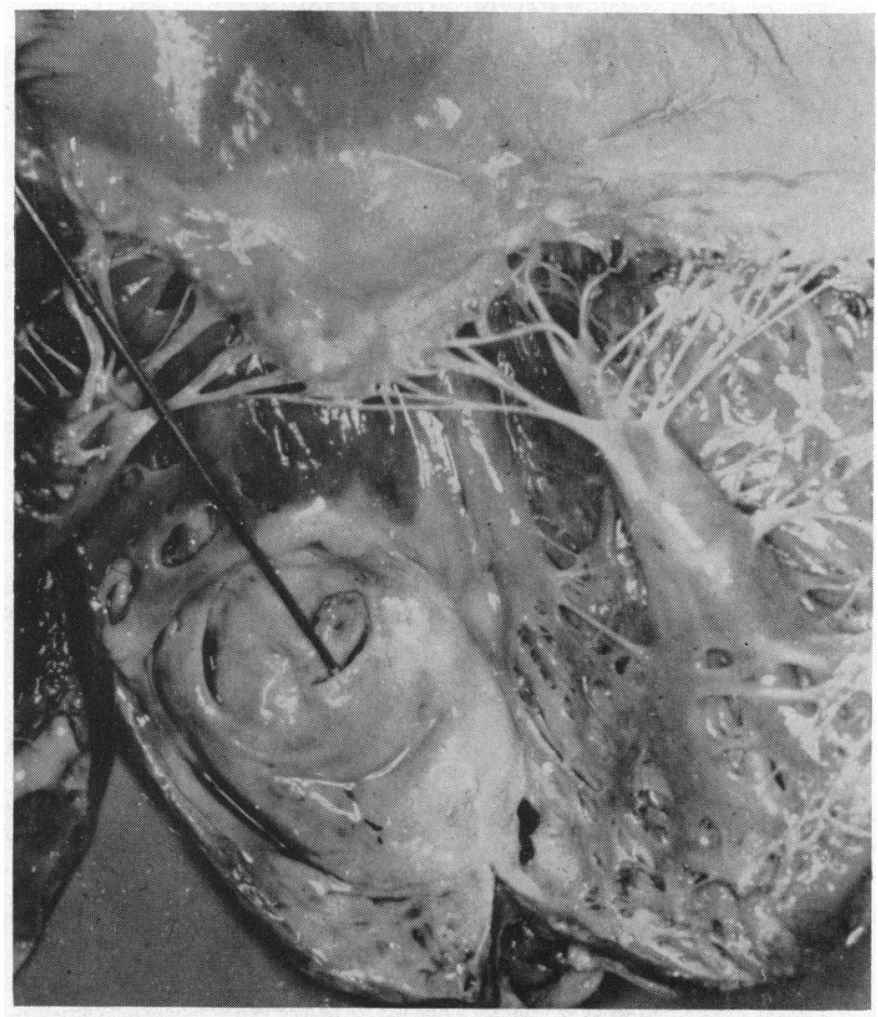

FIG. 2.-Open left ventricle with probe inserted into perforation of interventricular septum.

\section{Discussion}

Involvement of the interventricular septum is found in about 30 per cent of all autopsies in myocardial infarctions. On the other hand, septal perforation is infrequent and was described by Edmondson and Hoxie (1942) in 1.5 per cent of myocardial necroses, or 0.05 per cent of all autopsies performed. The septum was perforated in 19 per cent of all cardiac ruptures, according to the same author, while Sager (1934) met with septal involvement in only 3 per cent.

According to Sanders, Kern, and Blount (1956) more than 50 per cent of patients with septal perforation do not survive more than one week after the incident, and 87 per cent die within two months.

In our case the longevity after the perforation is outstanding. Apart from the case of Landale and Schlappi (1962) who survived for 13 years after the perforation of the interventricular septum and died from malignant disease, we were unable to find any report of survival lasting more than five years. Though we were not in a position to clarify the ultimate cause of death in our case, no connexion between his heart disease and the fatal outcome was evident. The prolonged survival may in part be explained by the comparatively low degree of coronary sclerosis.

It is almost certain that our patient survived for more than five years and two months, as clinical signs of septal perforation were already found on initial examination. The case history and the first electrocardiogram were suggestive of acute coronary disease having occurred about one month earlier. The possibility of a stenocardial attack in 1955 with perforated interventricular septum cannot be excluded. Late appearance of right bundle-branch block may be explained by fibrotic extension around the septal perforation. 
In contrast with the short and fulminant development in the majority of cases, the illness in our patient followed a benign course. He showed remarkable resilience under the stress of major surgery in spite of his age, anæmia, chronic chest infection, and recent coronary heart disease. The patient recovered without any complications. We have met with only one such case (Zucker et al., 1952) who, four years after septal perforation, was operated on for obstructive jaundice, but died soon after from pulmonary œdema.

The possibility of prolonged survival, even after major operation, lends support to possible surgical treatment of septal perforation following infarction. This has been performed successfully in two patients (Proudfit et al., 1959; Collis et al., 1962).

\section{Summary}

The case has been presented of an elderly man with chronic lung disease and anæmia in whom myocardial infarction complicated by perforation of the interventricular septum supervened. Later, subtotal gastrectomy had to be performed but he survived for more than five years after the septal perforation, ultimately dying from extracardiac causes.

The authors are grateful to Dr. W. J. Alkan, Head of Medical Department A for his advice and criticism, and to Dr. A. Reif, Head of the Pathological Department for his kind co-operation.

\section{References}

Brunn, F. (1923). Wien. Arch. inn. Med., 6, 533.

Collis, J. L., Mackinnon, J., Raison, J. C. A., and Whittaker, S. R. F. (1962). Lancet, 2, 172.

Cooley, D. A., Belmonte, B. A., Zeis, L. B., and Schnur, S. (1957). Surgery, 41, 930.

Edmondson, H. A., and Hoxie, H. J. (1942). Amer. Heart J., 24, 719.

Landale, D. G., and Schlappi, J. C. (1962). Amer. Heart J., 64, 33.

Proudfit, W. L., Tapia, F. A., McCormack, L. J., and Effler, D. B. (1959). Circulation, 20, 128.

Sager, R. V. (1934). Arch. intern. Med., 53, 140.

Sanders, R. J., Kern, W. H., and Blount, S. G. (1956). Amer. Heart J., 51, 736.

Schiller, K. F. R. (1960). Lancet, 2, 1322.

Zucker, R., Leibowitz., S., Brody, H., and Sussman, R. M. (1952). Arch. intern. Med., 89, 899. 